\title{
Deformation in the hinge region of a chevron fold, Valley and Ridge Province, central Pennsylvania
}

\author{
David K. Narahara* and David V. Wiltschko ${ }^{\dagger}$
}

Department of Geological Sciences. The University of Michigan. Ann Arbor, Michigan 48109. L.S.A

(Received 27 November 1984: accepted in revised form 18 July 1985)

\begin{abstract}
The hinge region of an asymmetrical chevron fold in sandstone, taken from the Tuscarora Formation of central Pennsylvania. U.S.A., was studied in detail in an attempt to account for the strain that produced the fold shape. The fold hinge consists of a medium-grained quartz arenite and was deformed predominantly by brittle fracturing and minor amounts of pressure solution and intracrystalline strain. These fractures include: (1) faults. either minor offsets or major limb thrusts, (2) solitary well-healed quartz veins and (3) fibrous quartz veins which are the result of repeated fracturing and healing of grains. The fractures formed during folding as they are observed to cross-cut the authigenic cement. Deformation lamellae and in a few cases. pressure solution. occurred contemporaneously with folding. The fibrous veins appear to have formed as a result of stretching of one limb: they cross-cut all other structures. Based upon the spatial relationships between the deformation features, we helieve that a neutral surface was present during folding, separating zones of compression and extension along the inner and outer arcs, respectively. Using the strain data from the major faults. the fold can he restored back to an interlimb angle of $157^{\circ}$; however, the extension required for such an angle along the outer arc is much more than was actually measured. This disparity between observed and required deformation suggests that the rest of the folding strain may be attributed to minor faulting, isolated severe pressure solution and to slight grain movements; we were not able to recognize the latter. We propose that a single episode of deformation produced the chevron fold causing the brittle deformation after the sandstone had been lithified. This brittle deformation was accomplished by faulting together with the translation of individual sandstone blocks which do not contain significant internal deformation.
\end{abstract}

\section{INTRODUCTION}

Most published mechanical analyses of folded sedimentary rocks have concentrated on folds in carbonates in large part due to the fact that several techniques exist for measuring strain magnitude and strain direction in these rocks. Not as much emphasis has been directed towards the understanding of deformation mechanisms in folded sandstones. In this paper we report on (1) the deformation features observed in the hinge region of a chevron fold in sandstone, (2) an attempt to quantify the relative amounts of strain due to each observed strain mechanism and (3) the testing of the results in (2) by restoring the fold through reverse application of these strains. The fold chosen for this study is well exposed, is regionally well understood and was thought to have easily recognizable deformation features on the basis of preliminary field work.

\section{Previous work}

Both kinematic and dynamic models of chevron fold development that have been proposed, to date, explain certain features of naturally occurring folds. Kinematic models have clarified the controls on locking angles and space problems which exist in the cores of chevron folds with the onset of significant limb dip (Ramsay 1967,

Present addresses: 3 Wisconsin Avenue. Delmar. New York 120.54. U.S.A

$\rightarrow$ Department of Geology and Center for Tectonophysics. Texas A \& M University. College Station. Texas 77843-3115. U.S.A.
1974, Williams 1980). Dynamic models have explained the role of thickness and rheology in determining the final fold shape and wavelength (Ramberg \& Johnson 1976, Ellen 1971, Johnson 1970)

There have been, however, few studies of the strain distributions and mechanisms within naturally occurring chevron folds. Ellen (1971) showed that the distribution of strain within folded chert beds of the Franciscan Formation do not vary uniformly from place to place. For example, radiolarian tests within folded chert beds of the Franciscan Formation are locally undeformed. Beach (1977) documented the principal stress directions which existed before and during the formation of a set of chevron folds by studying multiple vein arrays. Using the deformation lamellae technique, Scott et al. (1965) showed that layer-parallel shortening had occurred prior to folding in a minor fold in sandstone from the Valley and Ridge Province of the Appalachians. In all of these studies, there was not a sufficiently large set of data with which to determine the history of strain development in the fold.

Based on theoretical buckle-fold models, a fold will display a neutral surface with extension and shortening strain on the outer and inner arc, respectively. However, many studies of natural folds have yet to document such a response (see Spang \& Groshong 1981). For example, studies of strains in folded carbonates have shown that strains measured within grains are small because other competing strain mechanisms, such as pressure solution or layer-parallel slip, were more efficient in the prevailing physical conditions that were present during folding (Chapple \& Spang 1974, Spang \& Groshong 1981). As a result, in the investigation of our fold, we were prepared 


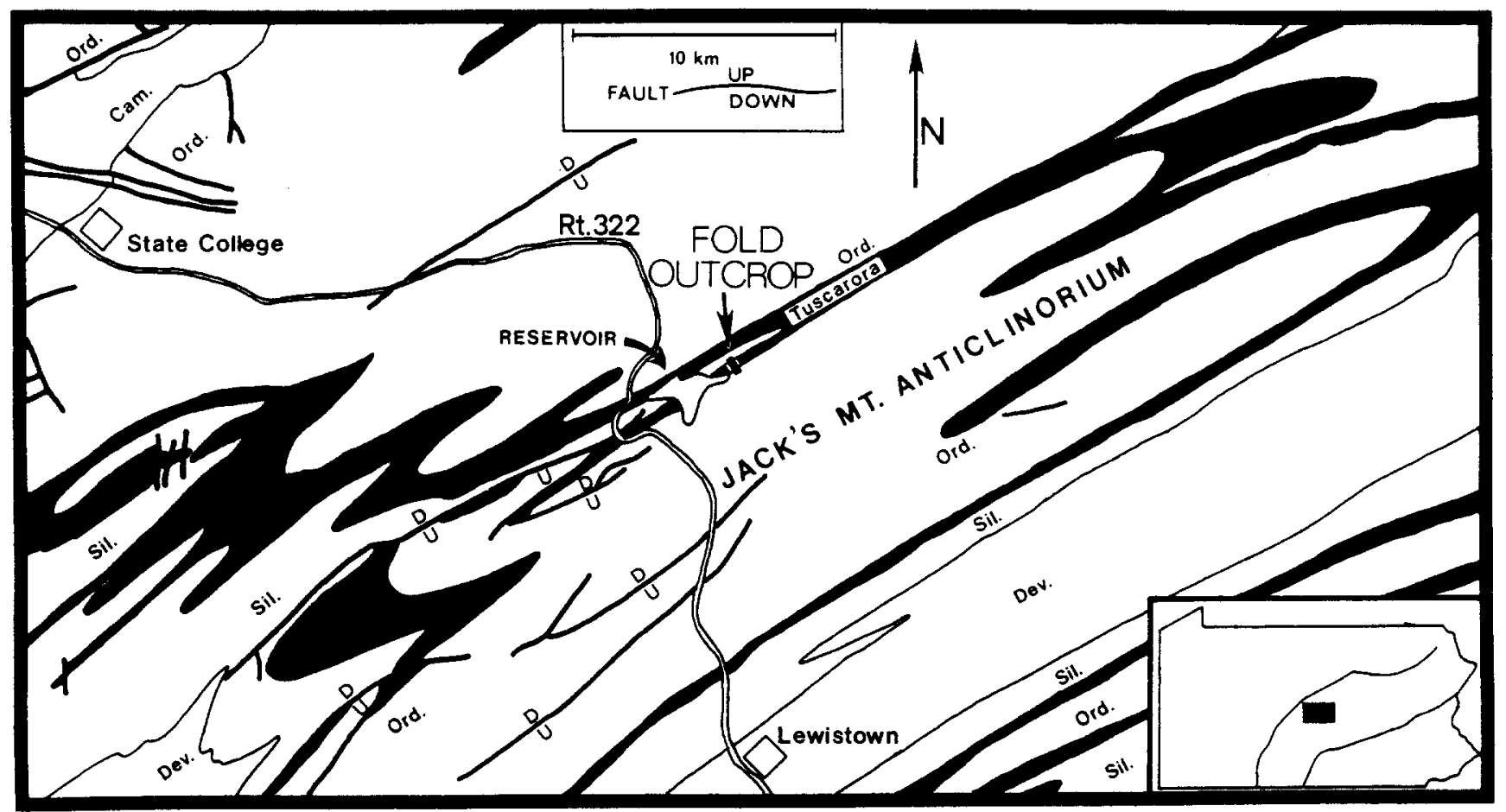

Fig. 1. Geological map showing location of 'the fold' outcrop. The black unit is the lower Silurian Tuscarora sandstone Other symbols: Ord., Bald Eagle and Juniata Formations; Sil., Rose Hill, Keefer. Mifflintown. Bloomsburg, Wills Creek and Tonoloway Formations; Dev., Keyser, Old Port, Onondaga, Marcellus, Mahantango and Trimmers Rock Formations. From the geological Map of Pennsylvania (Socolow 1980). Inset map shows location of main map area in Pennsylvania.

to find other mechanisms such as faulting and pressure solution which would accommodate the strain without significant intragranular deformation of individual quartz grains. Also, we were able to demonstrate the existence of a finite neutral surface.

\section{GEOLOGY}

\section{Regional}

The Valley and Ridge Province of Pennsylvania is composed of folds trending NE-SW, which formed as a result of a NW-SE shortening of the overlying strata. Faill (1973) describes these folds as having planar limbs, angular hinge zones and very little thickening of bedding within the hinge region. Presently, there is not a general consensus regarding the mechanics of fold formation in the Valley and Ridge Province. Many of the large regional folds are believed to have developed by the thrusting of strata over a series of ramps (Gwinn 1970, Perry 1979). The Valley and Ridge folds may in part be either buckle folds (Willis 1893) or intersecting kink bands (Faill 1973).

\section{Outcrop}

The fold outcrop is located on the northeast side of Laurel Creek reservoir. $16 \mathrm{~km}$ north of Lewistown, Pennsylvania (Fig. 1). Two pairs of well-exposed chevron folds are present, having an average interlimb angle of $65^{\circ}$. an amplitude of $6 \mathrm{~m}$, and an average axial orientation of $N 49^{\circ} \mathrm{E}, 8^{\circ} \mathrm{S}$ (Fig. 2). These folds lie within the slightly overturned northern limb of Jack's Mountain Anticlinorium. The chevron folds are in the correct position to be classified as drag folds (Ramberg 1963); one set of the downward-closing chevrons is asymmetrical in length, and the entire set of the chevron folds is overturned to the north. The folded layer that was studied in detail ranges from $5.7 \mathrm{~cm}$ to $7.0 \mathrm{~cm}$ in thickness for the right and left limbs, respectively, and the hinge region is $8.1 \mathrm{~cm}$ thick. The sample has an interlimb angle of $80^{\circ}$ (Fig. 3).

There are several outcrop-scale features which can be attributed to the folds shown in Fig. 2. These include: (1) striations, which lie on the bedding surfaces and are oriented perpendicular to the hinge line; (2) striated fault surfaces that trend subparallel to the hinge line and lie within the hinge region (Faill \& Wells 1973) and (3) bulbous hinges within the shale beds. Ramsay (1974) attributed the latter two features to space problems imposed by tightening of a multilayered sequence. There are also small-scale faults at high angles to bedding and large-scale thrust faults which cross-cut the folds and are thus postfolding features. Structures often found in folds, such as tension gashes or axial-plane cleavage, are absent at the outcrop. Except for those areas of the limbs adjacent to the nose regions, the fold limbs do not display much internal deformation that could be associated with folding.

\section{Hand specimen}

The fold that we studied is only one layer in the hinge region of a chevron fold that deforms at multilayered sandstone sequence. and will be subsequently referred 


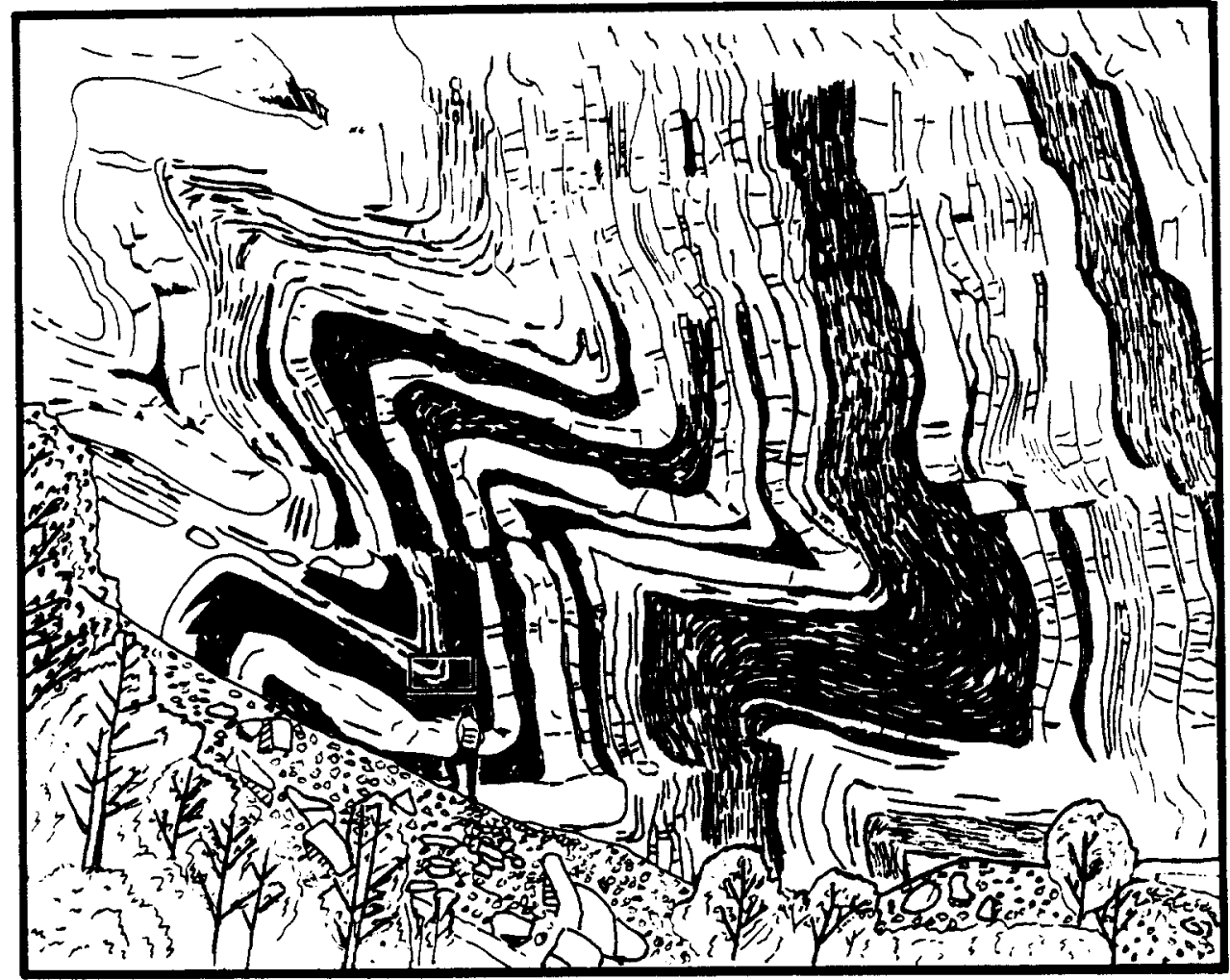

Fig. 2. Field sketch of two pairs of chevron folds exposed in a quarry within the Tuscarora Formation. Two faults lie horizontally at the middle and base of the outcrop. Person standing at the base of the quarry wall is facing northeast and is for scale. The structure illustrated in Fig. 3 is outlined by a box above the person.

to as 'the fold". The fold we have studied was taken from the lower Silurian Tuscarora Formation which at this site is conformable with the upper Ordovician Juniata Formation below and the middle Silurian Rose Hill Formation above. The Tuscarora Formation at this site consists of shale beds interbedded with well-cemented quartz arenites (sandstones containing greater than $95 \%$ silica). The individual sandstone beds range from 5 to $30 \mathrm{~cm}$ in thickness. The sample fold hinge contains subrounded and moderately sorted quartz grains, which are almost entirely cemented with silica. Minor mounts of clay are present within fractures, stylolitic seams, intergranular pores and deformed shale clasts. Cross laminations consisting of coarser quartz grains are inclined at $15^{\circ}$ to bedding. The laminae can be traced along the left limb and part way into the hinge region, but are not present on the right limb due to the severe fracturing.

The lithostatic pressure and temperature during deformation can be estimated in the following way. Using the stratigraphic thickness from the nearby Millerstown quadrangle (Faill \& Wells 1974), the original overburden may have been $4800 \mathrm{~m}$. Therefore, the minimum effective confining pressure could have been $120 \mathrm{Mpa}$ using a density of $2600 \mathrm{~kg} \mathrm{~m}^{-3}$. The temperature was approximately $190^{\circ} \mathrm{C}$ using a gradient of $40^{\circ} \mathrm{C} \mathrm{k} \mathrm{m}^{-1}$ ( see Nicols 1947 ).

\section{METHODOLOGY}

The fold was collected as five oriented pieces in the field and reassembled in the laboratory. The specimen was then cut into a $3 \mathrm{~cm}$ thick parallel-sided slab. perpendicular to the fold axis. The polished slab was then immersed in hydrofluoric acid to highlight the fractures (Fig. 4). This etched surface was then replicated by using rubber-silastic molds to ensure accurate positioning of the thin sections on a detailed map of the deformation features (Fig. 5). Mapping of the microstructures was aided by $(20 \times 25 \mathrm{~cm})$ black and white photographs of each thin section. Because the outlines of the detrital grains and fractures were virtually impossible to observe using a standard petrographic microscope, cathodoluminescence was used to map the silica cement and the host grains (see Sipple 1968, Zinkernagle 1978).

\section{DEFORMATION STRUCTURES}

Deformation in the sample has been primarily a brittle process and was accomplished by a combination of faulting, extension fracturing, pressure solution and minor intracrystalline mechanisms.

\section{Fractures}

Fractures are the most prevalent deformation features. They occur principally along the right limb-tohinge area and are almost absent from the left limb as shown on the etched surface of the fold (see Fig. 4). Three types of fractures in thin section are: (1) minor faults; (2) major through-going faults and (3) extension fractures. 


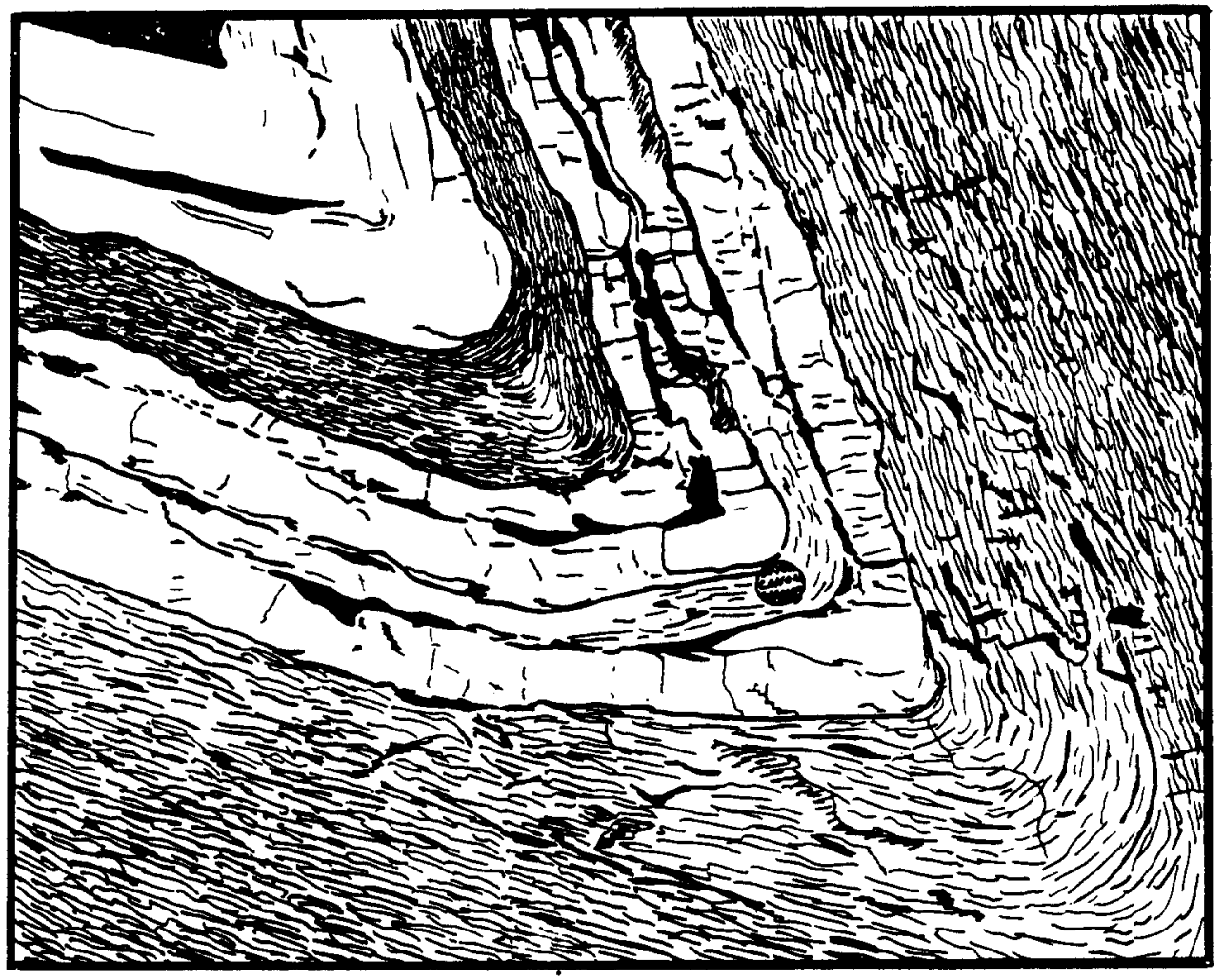

Fig. 3. Close-up of sample fold hinge (see Fig. 2) which is directly above the camera lens cover. center of picture. White beds are quartz arenites, darker beds are shales. Lens cover is $5.5 \mathrm{~cm}$ in diameter.

Minor faults. Minor faults having small indeterminate offsets are the most common structure but are not necessarily the most important in terms of displacement within the folded layer. There is a greater concentration of minor faults along the right limb, where the larger faults occur, than the left limb. Within the outer arc, the minor faults are at a high angle to bedding, while in the inner arc the faults are subparallel to bedding and have the same trend as the major thrust faults (see next section).

In thin sections, minor faults are partially to wellhealed zones that range from $5 \mu \mathrm{m}$ to $0.2 \mathrm{~mm}$ in width and 0.5 to $25 \mathrm{~mm}$ in length. The minor faults branch, or coalesce into single fractures instead of cross-cutting each other. In a few cases the sense of offset and the amount of displacement for the faults can be determined from the truncated grains. However, the grains cannot always be matched across the faults indicating that either (1) the offset was greater than a few grain widths or (2) the thin sections were not made parallel to the slip direction. or both.

The majority of the minor faults contain material between the fracture walls consisting of either comminuted quartz grains, microquartz (very fine grainsize) cement. blocky quartz cement or minor amounts of clay. The blocky spar cement is defined by euhedral quartz growth and slight undulatory extinction. This type of blocky infilling has been interpreted to represent rapid opening of a fracture followed by precipitation of cement (Misik 1971).

Major faults. There are two major through-going faults in the fold (Faults A and B. Fig. 5) and they are defined as having larger displacements and wider fault zones than the minor faults. These major faults are equivalent to the striated fault surfaces that were observed elsewhere at the exposure in the fold hinges. Both major faults terminate within the right limb and are surfaces along which sandstone is moved from the right limb towards the inner arc. Faults $A$ and $B$, have curvilinear shapes and under cathodoluminescence clearly truncate the authigenic quartz cement.

The two faults are quite different in thin section. Fault A ranges from 0.5 to $1 \mathrm{~mm}$ in width and contains cement which is similar in composition to that of a minor fault. The displacement along Fault $A$ is $13 \mathrm{~mm}$ as measured from the offset shale bedding (slide 2C-8, Fig. 5). Towards the middle of the folded layer (slide 2C-10, Fig. 5). Fault $A$ is no longer a single fracture. There. Fault $A$ branches into several shear fractures and finally terminates in an area of intense grain brecciation (Fig. 5). Thus, the displacement along Fault $\mathrm{A}$ is greatest at the top of the layer and appears to decrease towards the interior of the right limb.

The fault zone of Fault B is wider than that of Fault $A$ and consists of a system of many minor faults and extension veins. The extension veins have a shear component and are filled by large euhedral quartz grains. To determine fault displacement. it was necessary to locate where Fault B intersected the top of the bed. This occurred where (1) a portion of the overlying shale bed has been overthrusted by a wedge of sandstone (slide 2C-9. Fig. 5) and (2) the top shale bedding surface is striated. The leading edge of this wedge of sandstone is missing as indicated by the vertical striping on slide 2C-9 (Fig. 5). This missing wedge is reconstructed by extend- 


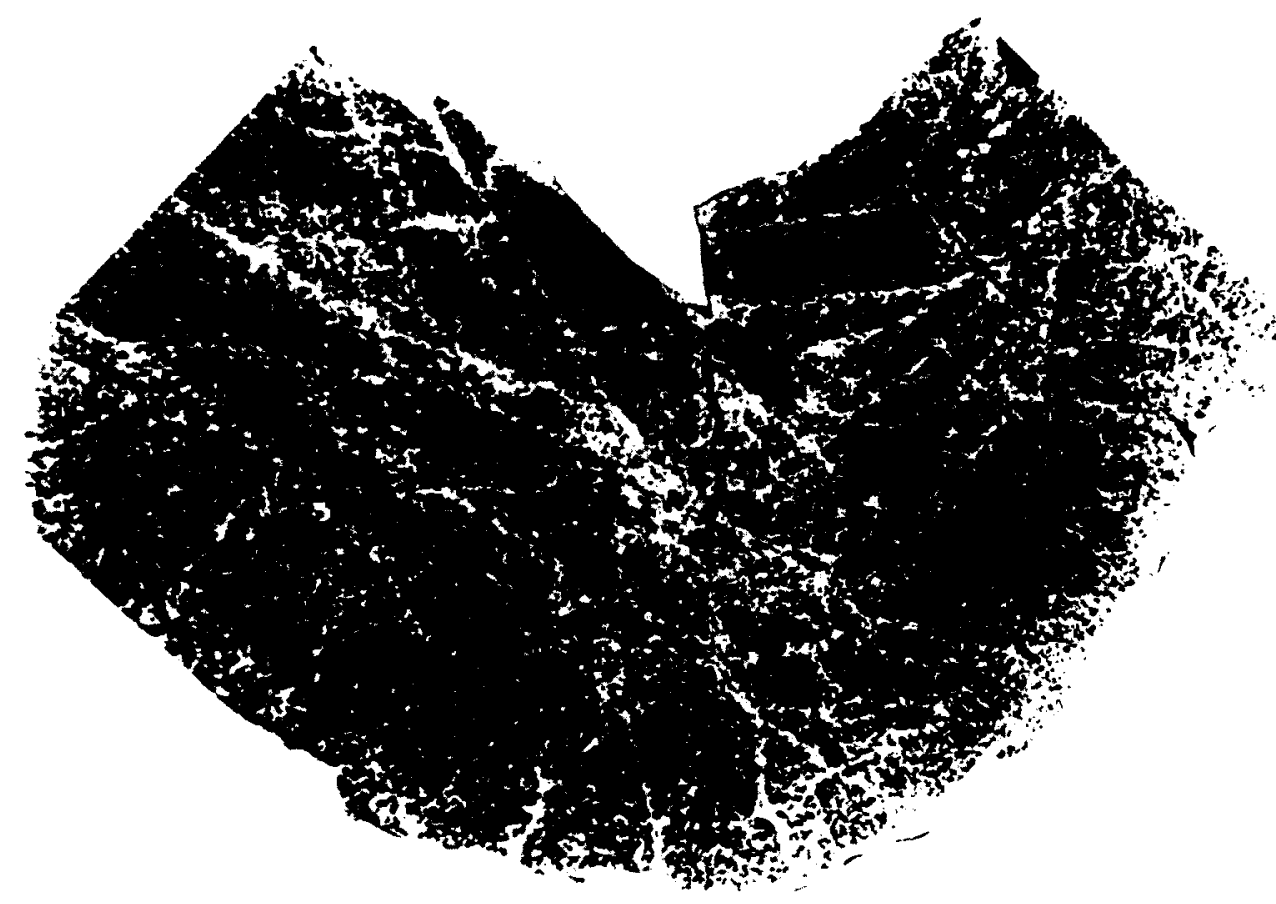

Fig. 4. Etched surface of the fold shown in Fig. 3. Faint white lines are fractures etched out by hydrofluoric acid. The photograph was taken by passing light through an epoxy replica which was painted and sanded lightly. Light areas are thus depressions on the replica and dark areas on the etched slab are the quartz grains.
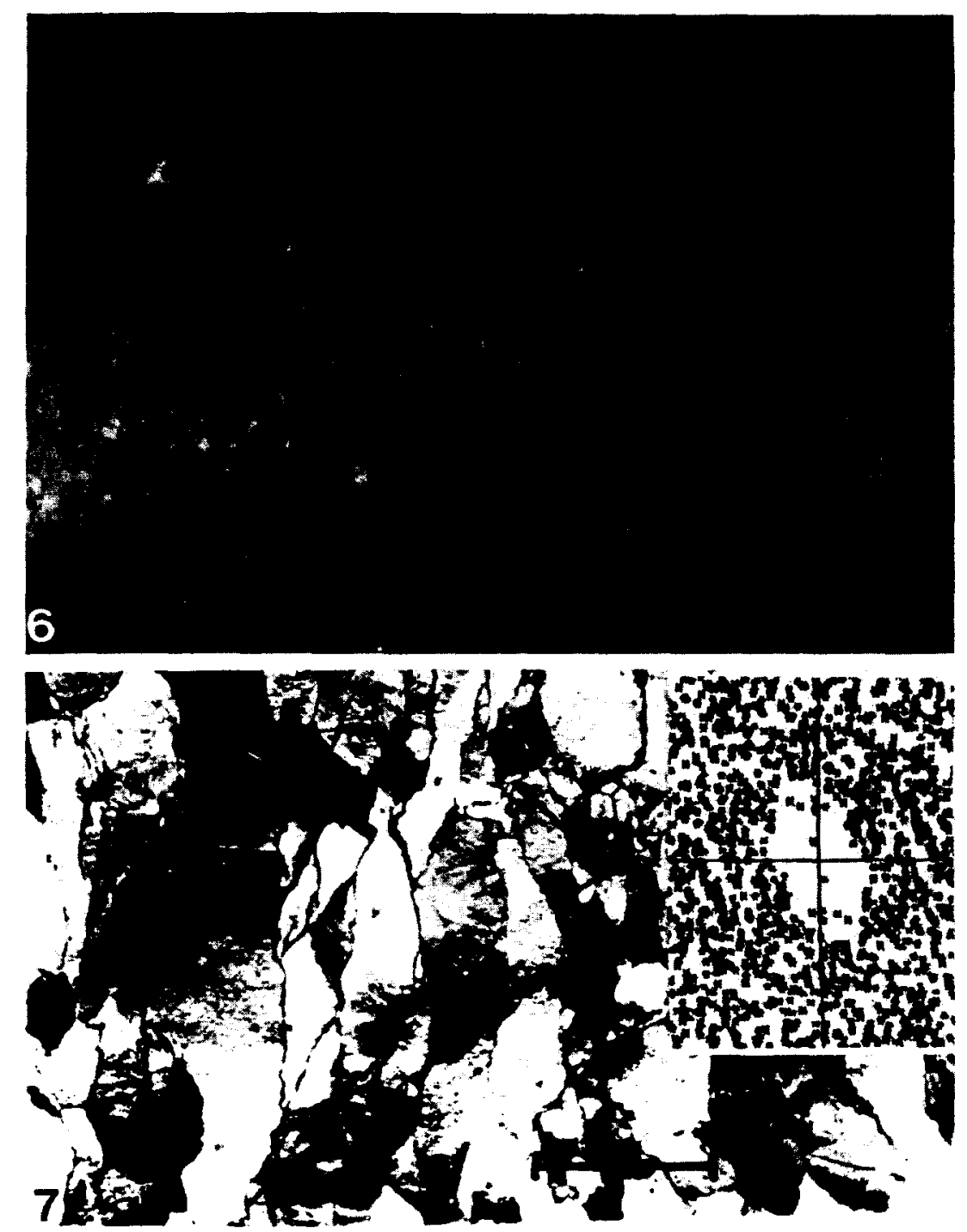

Fig. 6. Example of repeated fracturing and healing of an individual quartz grain (slide $2 \mathrm{C}-3$ ). The photograph was taken under cathodoluminescence. The host grain (light area) is cross-cut by quartz-filled fractures. See Fig. 5 for location of view. Scale bar is $0.25 \mathrm{~mm}$.

Fig. 7. Area within slide $2 \mathrm{C}-10$ showing the 'flattened' quartz grains. The vertical dark lines are clay selvages. Inset shows application of Fry strain technique to this area. Vertical and horizontal axes correspond to the thin section coordinates. See Fig. 5 for location of view. Scale-bar is $0.5 \mathrm{~mm}$. 


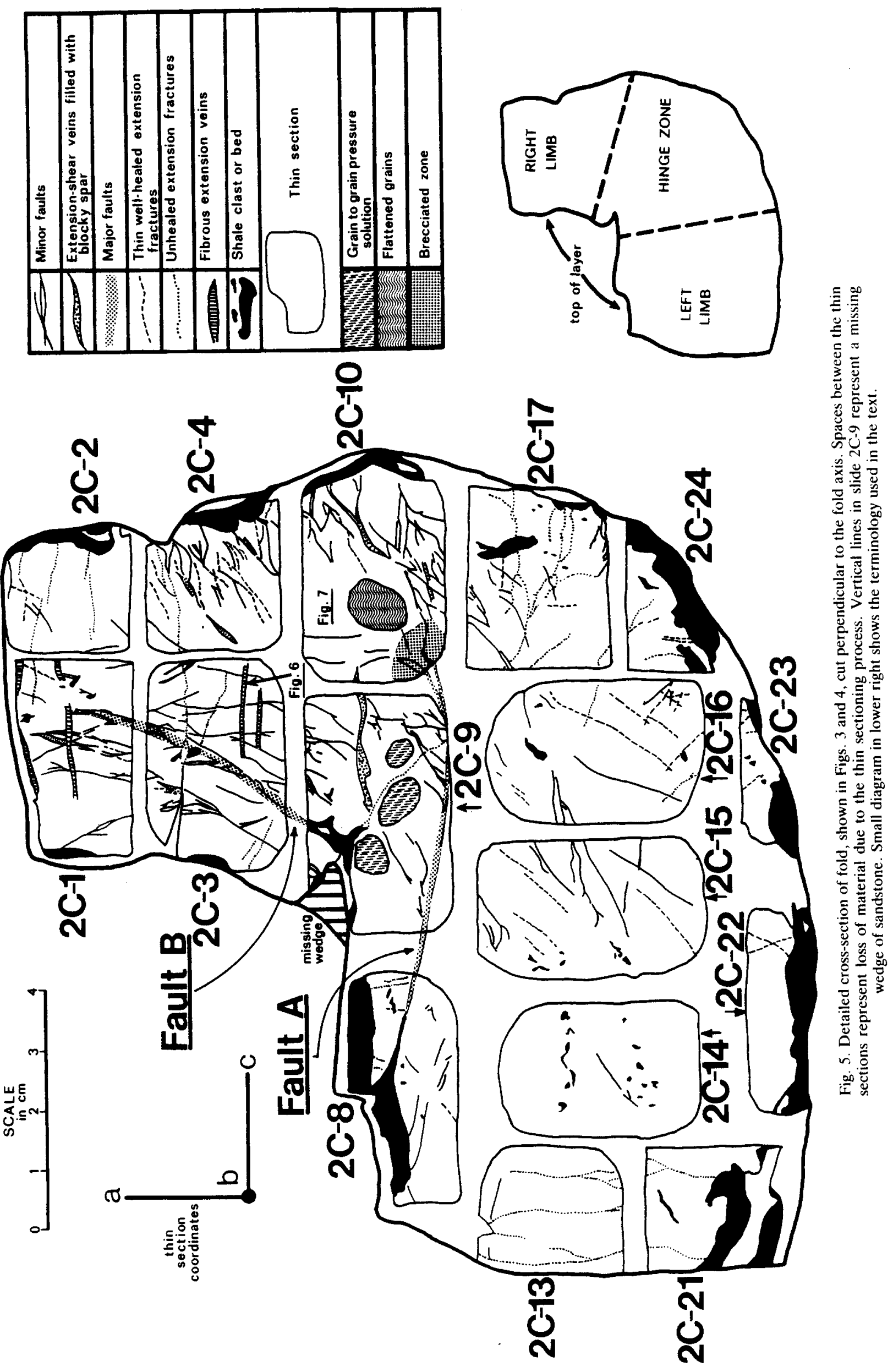


ing the top and bottom surfaces of the "thrust sheet' until they meet. The minimum displacement for Fault B is 24 $\mathrm{mm}$ as measured from the length of the underthrusted shale bed.

Extension fractures. There are three different types of extension fractures: (1) open unfilled fractures, (2) solitary well-healed fractures and (3) zones comprised of several healed extension fractures. Open fractures show no offset and usually contain no cement but in some cases are filled with clay or hematite. These fractures represent the open fractures seen in outcrop which are perpendicular to bedding. In thin section the fractures cross-cut all other structures but it is not clear whether they formed before, during or after folding.

The solitary fractures are thin quartz extension veins that lie within the outer arc. These quartz veins range from 0.05 to $0.3 \mathrm{~mm}$ in width. The minor faults within the outer arc have the same orientation as the quartz veins. For purposes of measuring the outer-arc extensional strain. the minor faults found there were also treated as thin extension veins, because the faults are only slightly displaced. The magnitude of the strain may be estimated by using a width ranging from 0.05 to 0.3 $\mathrm{mm}$ per fracture for the 45 fractures in the outer arc of length $145 \mathrm{~mm}$. The extensional strain for the outer arc ranges from 1.6 to $9.9 \%$ for fracture widths of 0.05 and $0.3 \mathrm{~mm}$, respectively.

The third type of vein is similar to the stretched grains described by Durney \& Ramsay (1973). Under crossed polars, the veins have a fibrous appearance and are difficult to observe because the silica cement grows in optical continuity with the host grain. Using cathodoluminescence, the veins consist of several parallel. filled veins which separate remnants of original grains (Fig. 6). These veins occur in two locations: (1) as long and narrow veins, along the inner arc of the right limb/hinge area and (2) as a broad area which contains pressure solution and severe intracrystalline strain (slide 2C-10. Fig. 5). The first location contains clear, undeformed quartz cement and numerous trails of bubble inclusions which parallel the edge of the vein. The width of veins ranges from 0.5 to $3 \mathrm{~mm}$ and the average length is $15 \mathrm{~mm}$. Under cathodoluminescence, these veins clearly cross-cut all other structures and postdate initial lithification of the rock.

The second location is in an area where the grains appear to have been flattened into ellipsoidal shapes (slide 2C-10. Fig. 7). The intragranular strain in this flattened area is represented by severe undulatory extinction. Using the Fry method (Fry 1979), an apparent axial ratio of 1.8 is indicated, with the long axis oriented at $22^{\circ}$ counter-clockwise from the vertical coordinate direction. Under cathodoluminescence, these flattened grains are shown to be the result of extreme fracturing and healing of individual grains, together with an unknown amount of pressure solution and intragranular strain.

\section{Deformation lamellae}

Deformation lamellae were analyzed in order to define better the stress directions during deformation in the sample. The deformation lamellae appear as either (1) very sharp, thin zones that appear brighter than the host grain or (2) thicker and darker lamellae that are filled with abundant bubble inclusions. Each type corresponds to one of the end-member types described by Carter \& Friedman (1965).

Thin sections $2 \mathrm{C}-1,2,9,10,13$ and 16 , together with their respective mutually perpendicular thin sections, were used for the dynamic analysis. Since the exact position within the fold of each grain that was used for the analysis of deformation lamellae is known. it is possible to plot the position of each grain on its corresponding thin-section photograph. The resulting plots show that the grains containing lamellae occur nearly as frequently within the unfractured zones as they do along the fractures.

The results of the dynamic analysis of quartz appear in Fig. 8. Applying the technique of Carter \& Friedman (1965), the $C$-axis of the less deformed portion of the grain ( $\mathrm{Cl}$, open circles) is connected to the $C$-axis of the more deformed zone ( $C 2$, solid circles) along great circles which should intersect at a point representing the maximum principal compressive stress direction. Similarly, great circle arrows drawn from the $C$-axis of the more deformed portion of the grain ( $\mathrm{C} 2$, solid circles) to the pole to lamellae (arrow head) should point towards the least compressive stress direction. The arrows point towards $\sigma_{3}$ if $\sigma_{1}=\sigma_{2}>\sigma_{3}$ or towards a great circle containing $\sigma_{2}$ and $\sigma_{3}$ for $\sigma_{1}>\sigma_{2}=\sigma_{3}$ (Carter \& Raleigh 1969). The diagrams for samples $2 C-1,2,9,13$ and 16 indicate maximum principal stress directions that are subparallel to bedding (Fig. 8). Slide 2C-10, however. shows a stress direction that is at a high angle to bedding within the outer arc of the fold.

The orientation of the least principal stress direction for each slide was not as precisely determined due to a smaller data set and greater scatter. For slides 2C-9, 10 and 13 , the arrows converge along a great circle which is perpendicular to $\sigma_{1}$, implying a general stress condition of $\sigma_{1}>\sigma_{2}=\sigma_{3}$. The arrows for slide 2C-16 cluster towards a unique position along the $\left(\sigma_{2} \sigma_{3}\right)$ plane, suggesting a $\sigma_{1}=\sigma_{2}>\sigma_{3}$ stress condition. The data for slides $2 \mathrm{C}-1$ and $2 \mathrm{C}-2$ are both too scattered and too few to make a reasonable judgement. Where $\sigma_{3}$ is uniquely defined (2C-16), $\sigma_{2}$ lies parallel to the hingeline, and for the other cases (slides 2C-9,10 and 13), the $\left(\sigma_{2} \sigma_{3}\right)$ plane is parallel to the hinge line and subperpendicular to bedding.

\section{Pressure solution}

The two types of evidence for pressure solution are (1) clay selvages and (2) sutured grain contacts. The selvages are found: (1) radiating ouwards from the few deformed shale clasts: (2) within some of the faults and (3) parallel 

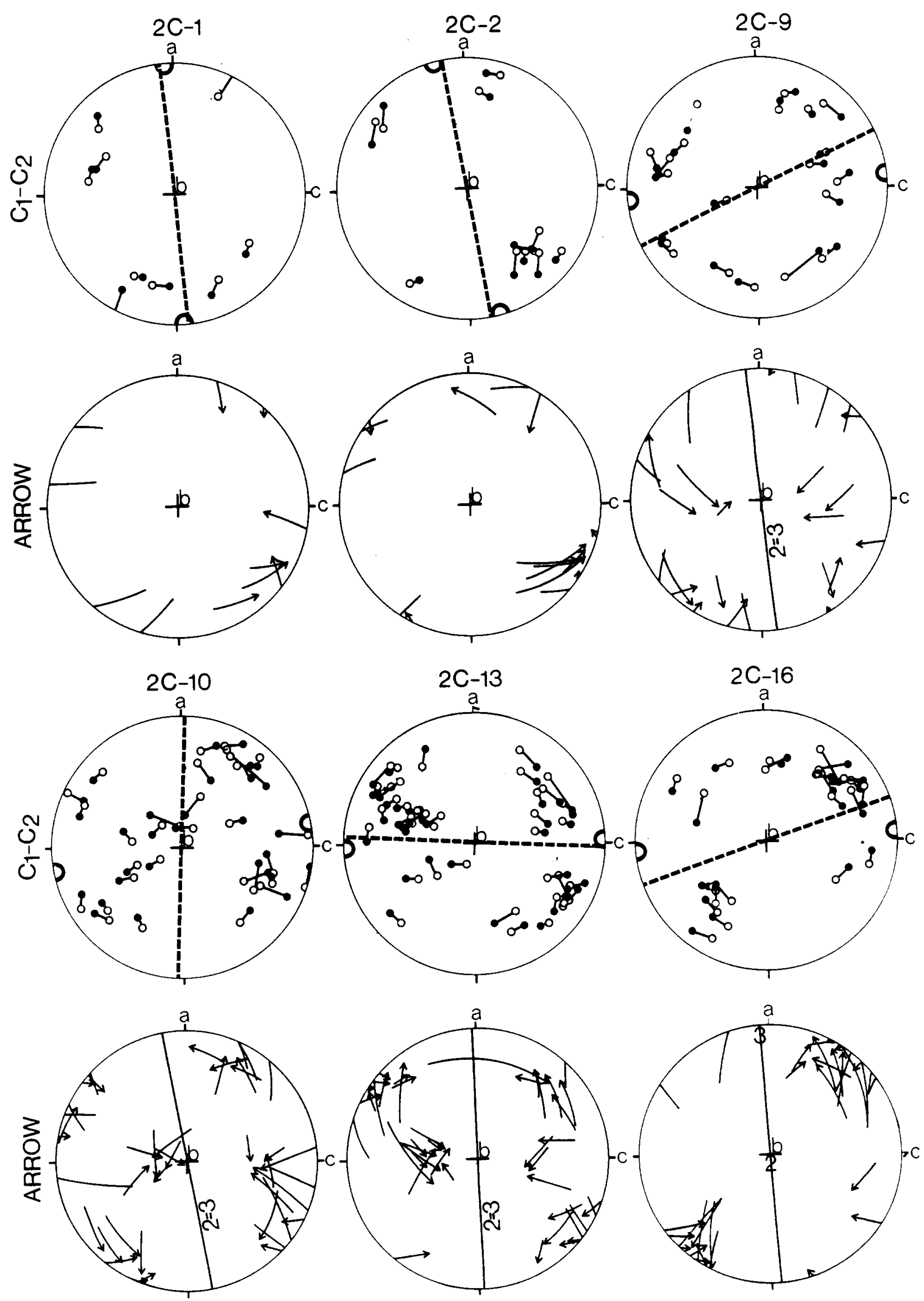

Fig. 8. Results of the deformation lamellae analysis applying the C1-C2 and arrow methods of Carter \& Friedman (1965) Freat circles are drawn from the $C$-axis of the less deformed portion of the grain $(C 1$, open circles) to the $C$-axis of the more deformed portion ( $C_{2}$, solid circles) and should intersect at a point which defines the principal compressive stress more deformed portion (C2, solid circles) and arrows (arrow-head is pole to lamellae, tail is $C$-axis of the more deformed portion of the grain) point towards the $\left(\sigma_{2} \sigma_{3}\right)$ principal stress plane (solid line). Bedding is represented by dashed lines portion of the grain) point towards the $\left(\sigma_{2} \sigma_{3}\right)$ principal stress plane (solid line). Bedding
The $a, b$ and $c$ coordinates are the same as in Fig. 5. 
to the elongated grains in slide $2 \mathrm{C}-10$. The selvages associated with the latter two structures are at least as old as the fractures as shown by the stylolitic teeth which truncate the fracture cement.

Pressure solution involving interpenetrating grains is restricted to areas which have higher amounts of clay and less silica cement. Slides 2 C-10 and 2C-9 (see Fig. 5) contain examples of grain suturing that are interpreted as occurring in areas that were poorly lithified by silica cement (see Sibley \& Blatt 1976).

\section{DISCUSSION}

\section{Timing of events}

The sequence of deformation mechanisms is outlined in Table 1. The fractures postdate the lithification of rock in the sample because the fractures occur in both the grains and the cement. This would be consistent with Sibley \& Blatt (1976) proposed, who suggested that Tuscarora sandstone was cemented early at shallow depths by connate waters.

We believe that the faults and the solitary, well-healed extension veins formed during folding. The major faults acted as limb thrusts during folding by moving material from the right limb towards the inner arc. However, they are not true contraction faults because they do not cut through the entire layer (cf. Spang \& Groshong 1981). The minor faults and the solitary extension veins, found along the outer arc, are attributed to folding because the angle between the fractures and bedding varies along the hinge region.

There are two possible conditions that could have yielded the principal stress directions inferred from the deformation lamellae analysis: (1) the lamellae formed during folding because the stress directions vary with respect to the bedding around the fold hinge and (2) the layer-parallel set of stress directions occurred during a prefolding. layer-parallel compression and the layerperpendicular direction (slide 2C-10, Fig. 5) is a result of synfolding compression. Had all of the lamellae formed prior to folding. such as during an earlier layer-parallel shortening stage. then all of the principal stress directions would have a constant orientation with respect to bedding (see Scott et al. 1965). Condition (2) is favored for this sample for two reasons. (1) It appears that the

Table 1. Timing of events. as interpreted from observation of structures in the fold shown in Figure 5

Event
$\begin{aligned} & \text { 1. Deposition of Tuscarora sandstone } \\ & \text { (Lower Silurian) }\end{aligned}$
2. Lithification of Tuscarora
(Age?)
3. Folding
(Alleghenian) Sunfolding mechanisms include major and minor
fauts, thin extension veins. deformation lamellae and pressure
solution

layer-parallel maximum stress directions were passively rotated during folding; if the lamellae had formed during folding, then the refraction of the stress field by the layer would not have yielded such consistent directions. (2) The layer-perpendicular stress direction (outer arc) is consistent with the stress field that produced the outerarc fractures

The age of the pressure solution in this specimen is not known, except where the selvages are found within the fractures or where fractures and selvages cross-cut each other as in the 'flattened' area of slide $2 \mathrm{C}-10$. This relationship shows that some pressure solution was occurring during fracturing, which for this sample, indicates formation of synfolding pressure solution. However, we were unable to determine the strain due to pressure solution.

The final stage of deformation occurred along the inner arc-right limb area and is represented by the long and narrow fibrous extension veins which cross-cut all of the other structures. The fact that the quartz cement inside the fibrous veins is nearly strain free suggests that this veining occurred during the latest stage of deformation in the specimen.

\section{Strain}

Although the strains along the major faults and across the thin extension veins can be measured (see Table 2), the remainder of the strain mechanisms can only be analyzed in a qualitative manner. As the maximum principal stress was perpendicular to layering and subperpendicular to the maximum elongation direction, along the outer arc (slide 2C-10, Fig. 5), this indicates that the outer arc was undergoing extension parallel to the bed. The quartz veins and the minor faults within the outer arc are subperpendicular to the bed along the right limb and more inclined to the bed along the left limb. These limb fractures also indicate layer-parallel extension along the outer arc, together with an indication of a counter-clockwise shear stress couple along the left limb. The inner arc of the fold, along the hinge and right limb. was compressed parallel to layering during folding as indicated by the layer-parallel orientations of the major and minor faults (Fig. 9). The existence of separate zones of compression and extension. along the inner and outer arcs, respectively, suggests that a neutral surface may have been present during folding.

Table 2. Strain measurements for the major faults and thin extension veins

\begin{tabular}{lccc}
\hline $\begin{array}{c}\text { Deformation } \\
\text { mechanism }\end{array}$ & Displacement & $\begin{array}{c}\text { Vein width } \\
(\mathrm{mm})\end{array}$ & $\%$ extension \\
\hline $\begin{array}{l}\text { Major faults } \\
\text { Fault } \mathrm{A}\end{array}$ & $1.3 \mathrm{~mm}$ & - & - \\
$\begin{array}{l}\text { Fault B } \\
\text { Thin extension }\end{array}$ & $24 \mathrm{~mm}$ & - & - \\
veins (outer arc) & - & $(0.05)$ & $1.6 \%$ \\
\hline
\end{tabular}

Line designates "not applicable" 


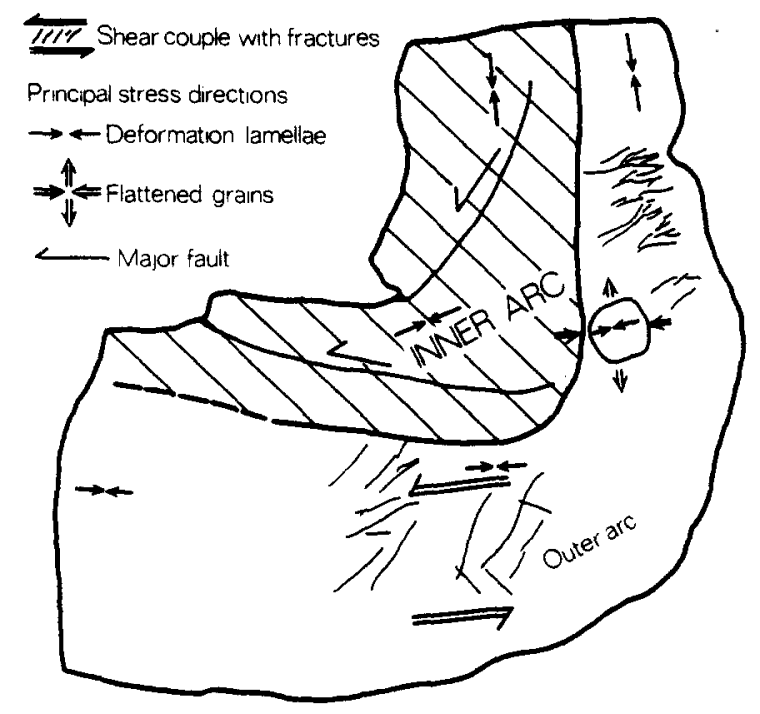

Fig. 9. Schematic diagram of the fold partitioned into an inner (diagonal striping) and outer arc. Each zone has a particular mode of deformation and a particular trend for the fractures.

Intracrystalline strain, which includes deformation lamellae and undulatory extinction, is a ubiquitous feature throughout the fold. However, the intensity of the intracrystalline deformation in the areas between the fractures is rather low, suggesting that deformation was accomplished mainly by fracturing. It seems likely that the interiors of rigid sandstone blocks were only slightly deformed while the blocks themselves were being translated along the faults.

The hinge region is thickened slightly as indicated by the faults within the hinge. This, plus the fact that most of the deformation features are present in the hinge and the right limb suggests that the left limb was rotated about the fold axis without significant internal deformation.

\section{Restoration of the fold}

An attempt was made to restore the folded layer by rotating the right limb about a fold axis while keeping the left limb fixed. If the strains we measured are approximately correct, then they should account for the $100^{\circ}$ of limb rotation which is necessary to unfold the fold. The constraints for unfolding the layer are the following: (1) the amount of limb rotation must result in the observed offsets along Faults $\mathrm{A}$ and $\mathrm{B}$ and (2) the unfolding must exactly close the extension on the outer arc (see Table 2 ).

Procedure. The axis of rotation for folding is assumed to lie somewhere near the termination of major Fault $\mathrm{A}$, or between it and the outer arc surface. This assumption is based on the conclusion that the upper half of the bed (inner arc) and the lower half of the bed (outer arc) were zones of shortening and extension, respectively. Moving the rotation axis towards the outer arc surface from the middle of the layer, reduces the amount of layer-parallel extension required for the outer arc. This repositioning appears necessary because of the low values of extension strain that were calculated for the outer arc.

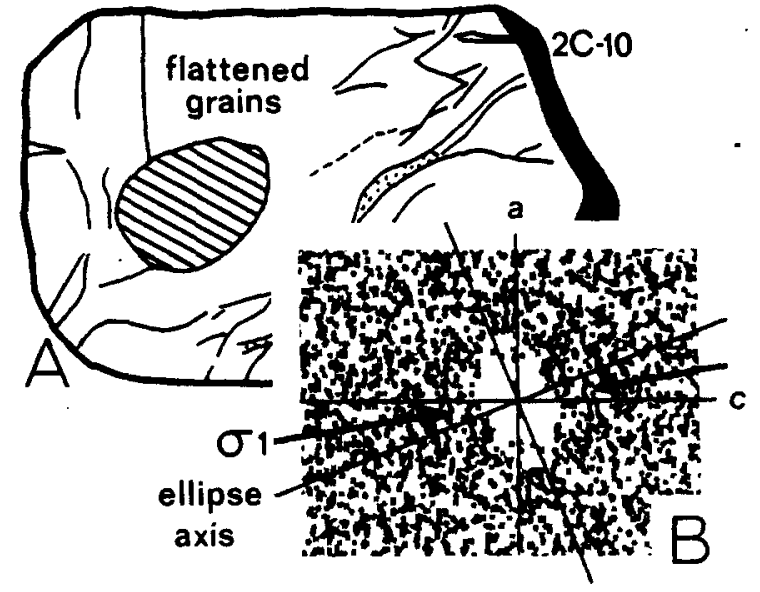

Fig. 10. (A) Close-up of slide $2 \mathrm{C}-10$ showing the approximate area of the ellipsoid-shaped grains (flattened grains). (B) Fry diagram showing the close correspondence of the principal compressive stress direction derived from deformation lamellae (arrows) and the strain ellipse direction (white area). See Fig. 5 for key to the microstructures.

A tracing of the right limb was placed on top of Fig. 9 and then rotated, with respect to the left limb, about one of four selected rotation axes (Fig. 11). This rotation produced 'extension' along the inner arc as the thrusted wedges of sandstone are pulled back and unfolded along Faults A and B. This procedure was carried out until the offsets along each major fault were matched across the fault.

As a result of 'extension' in the inner arc during unfolding, the outer arc was 'shortened'. The 'shortening' strain for each rotation axis was then compared with the calculated extension strains for the outer arc (Table 2).

\section{Results of unfolding the layer}

The results of unfolding the fold about each rotation axis are shown in Fig. 11 and listed in Table 3. As the rotation axis is positioned away from the outer arc surface and towards the neutral surface, the resulting interlimb angle and the amount of 'shortening produced along the outer arc are both increased. The rotation axis that best satisfies both constraints from the measured strains (Table 2) should lie somewhere between rotation axes 1 and 3 . However, to satisfy both strain constraints, the fold may be only restored up to a maximum interlimb angle of $120^{\circ}$. Thus, at least $60^{\circ}$ of layer rotation is unaccounted for during folding by the deformation mechanisms which have been identified.

This inability to complete the unfolding suggests either that we grossly underestimated the quantity of strain or that other unidentified strain mechanisms played important roles during folding, or both. The scale at which we mapped the microstructures suggests that our measurements are reasonably accurate.

Other deformation mechanisms that might be considered to be significant during folding are minor faulting and pressure solution. The alternatives of intracrystalline deformation and the long and narrow fibrous 


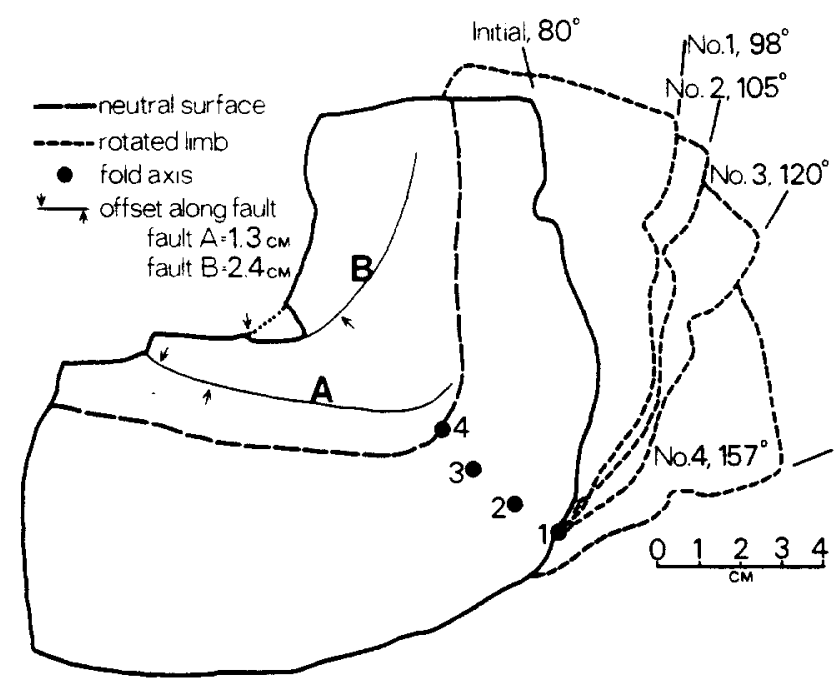

Fig. 11. Present position of fold (solid outline) and the position of the right limb (dashed outline) after rotation about a fold axis using the given fault displacements. The two numbers associated with each outline are, first. the identification number of the fold axis used, and second, the resulting interlimb angle.

extension veins are considered to be less important to the folding strain. The reasons for the latter conclusion are that intracrystalline deformation is poorly developed in the fold, and the fibrous extension veins are interpreted to be the result of a late-stage extension within the right limb.

The minor faults are quite abundant within the inner arc of the fold, suggesting that integration of their displacements is likely to increase the amount of compressional strain that was estimated from the major faults. Unfortunately, the majority of the minor fault offsets are unknown and thus their contribution to folding cannot be directly determined.

Pressure solution, like minor faulting, is another deformation mechanism in which the amount of strain in our specimen is unknown. Although there are few pressure solution selvages, the amount of strain attributed to any one stylolite could be locally high. A possible area is located in slide 2C-10, where the grains were flattened by a combination of stylolization. fracturing and intracrystalline deformation.

Another type of deformation that cannot be measured is grain-boundary sliding. Areas in the fold which contain less silica cement. higher amounts of interstitial clay and sutured grain contacts (slides 2C-9 and 10, Fig. 5), are areas which may have been susceptible to grainboundary sliding. However, techniques for the detection of grain-boundary sliding have not been developed and thus their contribution to strain in rocks is unknown.

Although the fracture patterns indicate layer-parallel compression and extension for the inner and outer arcs, respectively, the existence of a neutral surface is not demonstrable for the entire duration of folding. The small extensional strain for the outer arc suggests that a neutral surface may have been present, but for only a certain stage of folding. Because of the predominance of faults over the other structures in the fold, it is more likely that the majority of folding strain involved a form
Table 3. Results of unfolding the layet about each layer rotation axis (see Fig. 11)

\begin{tabular}{ccc}
\hline Fold axis & $\begin{array}{c}\text { Interlimb angle } \\
\text { (degrees) }\end{array}$ & $\begin{array}{c}\text { Shortening along } \\
\text { the outer arc } \\
(\%)\end{array}$ \\
\hline 1 & 98 & 0 \\
2 & 105 & 3.1 \\
3 & 120 & 9.9 \\
4 & 157 & 26.6 \\
\hline
\end{tabular}

of hinge collapse, in which faulting was the dominant deformation mechanism in the hinge zone and the adjacent right limb. The left limb, however, contains less deformation and thus folding must have been asymmetric.

\section{CONCLUSIONS}

The sandstone layer was deformed in a brittle manner during a single episode of folding (Alleghenian) and only after lithification of the rock. The conditions during folding appear to have been 'cold and brittle' as indicated by the depth of burial and the paucity of significant ductile strain features.

Overall, folding strain was accomplished by displacement of rigid sandstone blocks along a series of faults. Deformation within the blocks was limited to a small number of internally deformed grains. However. strain in the fold does not appear to have been uniform. A few of the faults and a few localized areas may have been the sites of severe deformation in the form of pressure solution, ductile strain in grains or grain-boundary sliding.

Faults, thin extension veins and some intracrystalline deformation features appear to have formed during folding. However, the timing of each deformation mechanism type may have been different during folding. It is suggested that faulting occurred in the hinge zone for much of folding, but the outer arc extension fractures existed only during the presence of an incremental neutral surface. Most of the deformation lamellae formed prior to folding, by layer-parallel shortening. However. some of the lamellae did develop during folding, as indicated by the layer-perpendicular direction within the outer arc. The long and narrow fibrous extension veins were formed after the outer structures and are not considered important to the actual bending of the layer.

The attempt to unfold the layer using the measured strains was only partly successful and suggests: (1) that the minor faults, if measurable. could be an important addition to the overall folding strain: (2) that the localized and highly deformed areas in the hinge zone are also important to the folding strain and (3) the possible occurrence of an undetectable deformation mechanism. such as grain-boundary sliding, occurred during folding.

Acknowledgements-We would like to thank Nick Nickelsen for early help in selecting a field site for this work. David $K$. Narahara was 
supported by a Scott Turner grant from the Geology Department, University of Michigan. Support to David V. Wiltschko was provided by NSF grant EAR NO. 82-12714. K. C. Lohmann provided help with the cathode luminoscope. Typing was expertly done by Cheryl Lackey at Texas A \& M University.

\section{REFERENCES}

Beach, A. 1977. Vein arrays, hydraulic fractures and pressure solution structures in a deformed flysch sequence, S.W. England. Tectonophysics 40, 201-225.

Carter, N. L. \& Friedman, M. 1965. Dynamic analysis of deformed quartz and calcite from the Dry Creek Ridge Anticline. Montana. Am. J. Sci. 263, 747-785.

Carter, N. L. \& Raleigh, C. B. 1969. Principal stress directions from plastic flow in crystals. Bull. geol. Soc. Am. 80, 1231-1264.

Chapple, W. M. \& Spang. J. H. 1974. Significance of layer-parallel slip during folding of layered sedimentary rocks. Bull. geol. Soc. Am. 85, 1523-1534.

Durney, D. W. \& Ramsay, J. G. 1973. Incremental strains measured by syntectonic crystal growths. In: Gravity and Tectonics (edited by De Jong, K. A. \& Scholten, R.). Wiley, New York, 67-96.

Ellen, S. D 1971. The development of folds in layered chert of the Franciscan Assemblage near San Francisco, California. Unpublished Ph.D. thesis, Stanford University, Stanford, California.

Faill, R. T. 1973. King-band folding, Valley and Ridge Province, Pennsylvania. Bull. geol. Soc. Am. 84, 1289-1314.

Faill, R. T \& Wells. 1973. Stratigraphy. In: Structure and SilurianDevonian Stratigraphy of the Valley and Ridge Province, Central Pennsylvania (edited by Faill, R. T.). Pennsylvania Bureau Topographic and Geologic Survey, Department of Environmenta Resources, 1-91.

Faill, R. T. \& Wells, R. B. 1974. Geology and mineral resources of the Millerstown quadrangle. Perry. Juniata and Snyder counties. Pennsylvania. Pennsylvania Geol. Surv. ser. 4. Atlas 136.

Fry, N. 1979. Random point distribution and strain measurement in rocks. Tectonophysics 60, 89-105.

Groshong, R. H., Jr. 1975. Strain, fractures and pressure solution in natural single-layer folds. Bull. geol. Soc. Am. 86, 1363-1376.
Gwinn, V. E. 1970. Kinematic patterns and estimates of lateral shortening, Valley and Ridge and Great Valley Provinces. Central Appalachians. South-central Pennsylvania. In: Studies of Appalachian geology: Central and Southern (edited by Fischer, B. W.. Pettijohn, F. J. \& Weaver. K. N.). Wiley, New York, 127-146.

Johnson. A. M. 1970. Physical Processes in Geology. Freeman, Cooper \& Co. . New York.

Misik. M. 1971. Observations concerning calcite veinlets in carbonate rocks. J. sedim. Petrol. $41,450-460$.

Nichols. E. A. 1947. Geothermal gradients in mid-continent and Gulf Coast oil fields. Am. Inst. Min. Metall. Engng, Petrol. Div.. Petrol. Dev. Tech. Trans. 170, 44-50.

Perry, W. J. 1979. Sequential deformation in the Central Appalachians. Am. J. Sci. 278. 518-542

Ramberg. H. 1963. Evolution of drag folds. Geol. Mag. 100. 97-106. Ramberg. I. B. \& Johnson, A. M. 1976. Asymmetric folding in interbedded chert and shale of the Franciscan Complex, San Francisco Bay area, California. Tectonophysics 32, 295-320

Ramsay, J. G. 1967. Folding and Fracturing of Rocks. McGraw-Hill. New York.

Ramsay, J. G. 1974. Development of chevron folds. Bull. geol. Soc. Am. 85, 1741-1754.

Scott, W. H., Hansen, E. \& Twiss, R. J. 1965. Stress analysis of quartz deformation lamellae in a minor fold. Am. J. Sci. 263, 729-746.

Sibley, D. F. \& Blatt, H. 1976. Intergranular pressure solution and cementation of the Tuscarora orthoquartzite. $J$. sedim. Petrol. 46 881-896.

Sipple, R. F. 1968. Sandstone petrology, evidence from luminescence petrography. J. sedim. Petrol. 38, 530-554.

Socolow, A. A. 1980. Geological map of Pennsylvania (edited by Miles, C. E.). Pennsylvania Bureau Topographic and Geologic Survey. Department of Environmental Resources, scale $1: 250,000$

Spang, J. H. \& Groshong, R. H., Jr. 1981. Deformation mechanisms and strain history of a minor fold from the Appalachian Valley and Ridge Province. Tectonophysics 72. 323-342.

Williams, J. R. 1980. Similar and chevron folds in multilayers using finite-element and geometric models. Tectonophysics 65, 323-338.

Willis. B. 1893. The mechanics of Appalachian structure. 13th Ann Rep. U.S. Geol. Surv.

Zinkernagle, V. F. 1978. Cathodoluminescence of quartz and its application to sandstone petrography. Contr. Sediment. 8, $1-69$. 